International Journal of Health Sciences
Available online at www.sciencescholar.us
Vol. 6 No. 1, April 2022, pages: $398-404$
e-ISSN: 2550-696X, p-ISSN: $2550-6978$
https://doi.org/10.53730/ijhs.v6n1.4627

\title{
The Nursing Internship in COVID-19 Times
}

\author{
(1) croshath \\ María Liliana Calderón Macías a , María del Rosario Herrera Velázquez ${ }^{\text {b }}$, \\ Aida Monserrate Macías Alvia c, Gema Margarita Reyes Avila d, María Jacqueline Macías Alvia e
}

Manuscript submitted: 30 September 2021, Manuscript revised: 3 December 2021, Accepted for publication: 26 January 2022

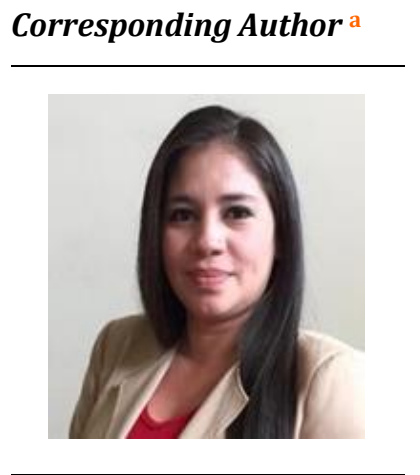

Keywords

COVID-19;

health care;

health insurance;

nurse;

practices clinics;

public health;

SARs CoV2;

\begin{abstract}
The objective of the research is to know how nursing students fulfill the rotating internship service, knowing that this is a mandatory program in medicine, nursing, obstetrics, and nutrition careers in higher education institutions in Ecuador. To complete this program, students apply and deepen the knowledge acquired in their previous levels of training. An analysis of the situation of intern nursing students during the pandemic caused by SARs CoV2 is presented. The regulations for the development of the internship were analyzed, evidencing educational gaps in biosafety matters and it became necessary to reorient the current regulations for the realization of the rotating internship and other clinical practices in terms of the functions of the interns and the obligations of the establishments of Health. It is concluded that the rotating nursing internship program must be reviewed and analyzed to prevent students from risking their physical and mental health in practice, for this, the Ministry of Public Health of Ecuador and the universities must reorient interinstitutional agreements towards the health care and optimal training of future professionals.
\end{abstract}

\section{Contents}

Abstract

1 Introduction

2 Materials and Methods.

3 Results and Discussions

4 Conclusion

\footnotetext{
${ }^{a}$ Universidad Estatal del Sur de Manabí, Jipijapa, Ecuador

b Universidad Estatal del Sur de Manabí, Jipijapa, Ecuador

c Universidad Estatal del Sur de Manabí, Jipijapa, Ecuador

d Hospital General del Norte de Guayaquil Los Ceibos, Guayaquil, Ecuador

e Universidad Estatal del Sur de Manabí, Jipijapa, Ecuador
} 


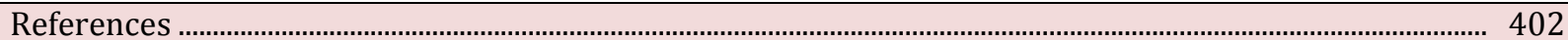

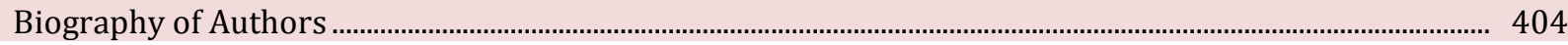

\section{Introduction}

The rotating internship is a mandatory program, developed by the medicine, nursing, obstetrics, and nutrition careers of all higher education institutions in Ecuador, to ensure that students apply and deepen the knowledge acquired -in their previous levels of training - during one year of teaching assistance service in the public health institutions of the country (NTIR In Health Establishments, 2019). In the nursing career, this program is developed in the last two semesters of training (eighth and ninth) divided into consecutive rotations in community care and hospital care scenarios, under the tutorship of a supervising teacher from the university to which it belongs (Asedefe \& Renace, 2014). During this calendar year, students become part of the health-contingent and provide services in health institutions as interns or fellows (Wang \& Luo, 2005; Haines et al., 2006).

Despite the arrival in Ecuador of the pandemic caused by the SARs CoV2 virus in February 2020, this program has continued to develop, however, the pandemic has wreaked havoc not only on the health of the inmates but also on their health programs. training, opening a debate between meeting learning objectives as students (Tapia et al., 2021) and the risk involved in being part of the first line of health care (De Bortoli et al., 2020).

\section{Materials and Methods}

For the development of the research, the inductive-deductive method was applied, based on a bibliographical review, analysis of reliable information related to the regulations that are applied in the stage of development of the internship in nursing students, in addition, it was had into account the observation and quantitative studies carried out in the pandemic era where results affected the involvement of nursing internship students.

\section{Results and Discussions}

According to the Organic Law of Higher Education and the Regulations of the Academic Regime that govern higher education in the country, undergraduate students before graduation must carry out a program of preprofessional internships to apply the knowledge acquired during training and develop the professional skills established by the graduation profile of the career (Ngomane \& Mulaudzi, 2012; Jungheim et al., 2010), in the case of nursing these practices are recognized as rotating internships and correspond to the training of 120 monthly hours of practice in care services of the comprehensive public health network during a calendar year (Organic Law of Higher Education, 2018); (Regulation of Academic Regime, 2019). During this period, the intern does not lose student status, so it is necessary to be accompanied by a teaching assistance tutor who will complete a total of 2 hours a day of teaching, supervision, and evaluation for the duration of the internship (Cóndor \& Palomeque, 2021), and will continue to receive 10 hours of weekly theoretical training in person or virtually as established (Technical Standard for Teaching Assistance Units, 2015).

\section{The intern as an in-service intern}

By the regulations established for this program, the student signs a contract for the provision of services without a dependency relationship (Stern et al., 2001; Baruch et al., 2008), as an intern with the institution in which the internship will be carried out, committing to comply with the schedules and established rotations, norms, and protocols of each service in which he performs his internship and other tasks entrusted to him, for this reason, he receives an economic recognition of $\$ 540$ per month, of which $17.60 \%$ is deducted for affiliation to the general health insurance for the duration of their teaching assistance service, having the right

Macías, M. L. C., Velázquez, M. del R. H., Alvia, A. M. M., Avila, G. M. R., \& Alvia, M. J. M. (2022). The nursing internship in COVID-19 times. International Journal of Health Sciences, 6(1), 398-404. https://doi.org/10.53730/ijhs.v6n1.4627 
to the same benefits as a member in a dependency relationship in terms of insurance for death, occupational risk, medical assistance, disability, etc. (Technical Standard for Teaching Assistance Units, 2015; Regulations for Assurance, Collection and Portfolio Management, 2018; Ministry of Public Health, 2021). If the intern cannot complete the established hours of teaching assistance service, whether due to domestic calamity, illness, or non-approval of the rotation, they must compensate those hours at the end of the rotating internship period, without the right to economic recognition (Norm Rotating Internship Technique in Health Establishments, 2019).

\section{The situation of the nursing intern during the COVID-19 pandemic Regarding}

The reported cases of the effects of the COVID-19 pandemic on nursing interns in Ecuador, there is evidence of 4 published national studies. The first study shows that $44 \%$ of 79 rotating interns contracted the SARs-CoV2 virus while carrying out their hospital practices from April to September 2020, while mentioning as a probable cause of this infection the use of masks not suitable for handling this type of acute respiratory infection and the incorrect removal of personal protection garments, including the mask; It is worth mentioning that the symptoms presented were mild and that once diagnosed, all fulfilled mandatory quarantine for 14 days (Loor Quiñonez \& Herrera Velázquez, 2020).

Another study carried out with nursing interns who provided service during the pandemic reports a $24 \%$ infection by SARs-CoV2 in students, and the use of inadequate personal protective equipment, as well as its incorrect use, is mentioned as a source of infection. or the non-use in the case of the eye protector or the surgical cap (Barahona Morillo, 2021). A specific study on the degree of stress of working nursing interns during the pandemic revealed that their level of exhaustion was medium while mentioning that over $30 \%$ of interns experienced verbal abuse by users, which led them to develop a lack of sensitivity during patient care in $22 \%$; In another part of the study, it is revealed that over $65 \%$ presented anxiety and fear of the risk of contamination and daily coping with multiple deaths due to the pandemic; Regarding the excess workload, $58 \%$ experienced this situation ( Barros Macías \& Ramos Herrera, 2020).

A fourth study dealt with the experiences lived by the inmates who were infected with COVID-19, who mention that the symptoms presented during the disease were mild and pointed to the lack of supplies in the first months of the pandemic and the incorrect use as a cause of contagion (Clifton \& Mann, 2011; McCaughey \& Traynor, 2010; Kumaran \& Carney, 2014). of personal protection equipment; Concerning mental health, they experienced fear and concern about the prognosis of the disease and subsequent rejection by their relatives for considering them a source of contagion even though they had already overcome the disease; this is the only study in which it is mentioned that the students received support and follow-up from the university student welfare unit and from the institution in which they served (Sisalema, 2021; Amir et al., 2021).

\section{Important aspects of discussion/reflections}

The above reveals a series of situations that the rotating intern goes through as a student and as part of the front-line team during the COVID-19 pandemic. The first aspect is related to the risk of physical and mental health deterioration to which students are exposed during direct patient care. This fact was a common denominator in several publications reviewed by the authors, where work stress (Betancourt et al., 2020); (Martín Sánchez, 2019); emotional instability (Merchan et al., 2020); (Mera Navarrete et al., 2021), the constant worry about getting sick and infecting their family have been reported by several authors. In contrast, we find the position taken in this regard by the Ministry of Public Health (MSP) as the contracting entity, which -for the effects of the pandemic- decided to leave the participation of interns in the rotating internship program under the responsibility of the universities, as well as their physical integrity, while stating that their "attendance at health establishments represents a potential risk of contagion for patients, medical personnel and for themselves" (Resolution of the Ministry of Public Health, 2020). Given that the program continued its course during the pandemic, the MSP included a clause in the service provision contracts of the inmates clarifying that this type of contract does not give rise to an employment relationship or any dependency and does not generate labor or administrative rights or obligations (Ministry of Public Health, 2021). 
However, in practice, it was shown that the students manifested work overload, perhaps due to the daily absences of nursing staff who entered quarantine for having contracted the disease or for suspicion of it. Regarding this, until September 2020, the MSP reported 2,182 cases of COVID-19 in professional nurses and 4,221 suspected cases that complied with preventive isolation pending results (Redacción, 2020).

As for the students, it is clear that they are at a crossroads when considering the rotating internship as an opportunity to put into practice what they have learned and develop professional skills, but also as a risky situation in the presence of COVID-19 and other diseases, which not only does it mean getting sick themselves and their relatives- but in the most serious cases, dying; they are also aware that this program is a degree requirement as established by law. These concerns were expressed in due time by the students involved, requesting the non-suspension of the rotating internship program during the pandemic, as this meant a delay in their academic training, while at the same time requesting the institutions involved to provide personal protective equipment. to start their work (Veletanga, 2020).

For higher education institutions, especially those that train future nurses, the educational gaps in biosafety are evident, although it is true that this generation had not previously faced a pandemic, according to the curricula of nursing careers in the country, learning about biosafety are cross-cutting axes in most curricula (Calderón Macías, 2018; Kistan et al., 2020). Several authors agree that in the training process as professionals, the students were not prepared to face and deal with a health emergency such as the pandemic, so the majority when faced with the new experience of the boarding school in conditions of the pandemic, uncertainty, fears and doubts overwhelmed them with the desire to put into practice what they learned in university classrooms (Pizarro et al., 2021; Widana et al., 2021).

This pandemic makes clear the importance of complying with biosafety protocols (Espín-Arguello, 2020), the need to know the handling, use, and disposal of personal protective clothing, the immediate response of preventive isolation, and the timely recognition of symptoms on the spread of diseases, these aspects become key topics for the revision and updating of the curricula of health careers. It is also necessary that the vaccination programs and plans be complied with, where internists and nurses must be a fundamental element in the process of their dissemination (Fischer, 1999), they have a substantial role in the care of the patient infected with the coronavirus disease as well as in the strategy of achieving the immunization of the population is fulfilled (Suryasa et al., 2021).

\section{Challenges}

The students of the rotating internship face different challenges and challenges from the new regulations and provisions for their compliance:

Reorient the regulations established for the realization of the rotating internship and other clinical practices, in terms of the functions of the interns as students and the obligations of the health establishments as the receiving institution of their services. Review and update the curricula on biosafety, pandemic, and disaster management, to avoid the deterioration of the health of students during clinical practice. Urge universities on the importance of carrying out a personalized follow-up of each student by the student welfare units, especially in the aspects of prevention and recovery of mental health, especially in times of epidemics and disasters that are becoming more and more common in our region.

\section{Conclusion}

The rotating internship program in nursing should be reviewed and analyzed to prevent the participation of students in learning activities during clinical practice from becoming a risk to their physical and mental health, for this purpose the Ministry of Public Health of Ecuador and the universities must review the interinstitutional agreements established for its effect and reorient them towards health care and optimal training of the future professional.

\section{Acknowledgments}

The group of researchers, who supported the research work, is praised; in addition to the editors of the journal for allowing us to publish this work.

Macías, M. L. C., Velázquez, M. del R. H., Alvia, A. M. M., Avila, G. M. R., \& Alvia, M. J. M. (2022). The nursing internship in COVID-19 times. International Journal of Health Sciences, 6(1), 398-404. https://doi.org/10.53730/ijhs.v6n1.4627 


\section{References}

Amir, F., Suhron, M., \& Sulaihah, S. (2021). Family care model development in treating schizophrenia patients that have self-deficit nursing based system: Structural equation modeling analysis. International Journal of Health \& Medical Sciences, 5(1), 7-14. https://doi.org/10.21744/ijhms.v5n1.1808

Asedefe, \& Renace. (2014). National Rotating Nursing Internship Program.

Barahona Morillo, A.P. (2021). Knowledge and application of biosafety standards against COVID-19 in rotating nursing interns UTN 2020-2021. North Technical University.

Barros Macías, H. D., \& Ramos Herrera, A. C. (2020). Coping with work stress in nursing interns in the COVID19 context (Doctoral dissertation, University of Guayaquil, Faculty of Medical Sciences, Nursing Career).

Baruch, S., Kaufman, D., \& Hudson, K. L. (2008). Genetic testing of embryos: practices and perspectives of US in vitro fertilization clinics. Fertility and sterility, 89(5), 1053-1058. https://doi.org/10.1016/j.fertnstert.2007.05.048

Betancourt Delgado, M.T., Domínguez Quijije, W.F., Peláez Flores, B.I., \& Herrera Velázquez, M.R. (2020). Occupational stress in nursing staff in the ICU area during the COVID 19 pandemic: Occupational Stress during the COVID Pandemic. UNESUM-Sciences, 4(3), 41-50.

Calderón Macías, M.L. (2018). The study plan for the nursing degree in Ecuador, from the external evaluation.

Clifton, A., \& Mann, C. (2011). Can YouTube enhance student nurse learning?. Nurse education today, 31(4), 311-313. https://doi.org/10.1016/j.nedt.2010.10.004

Cóndor Bermeo, V., \& Palomeque Terán, A.F. (2021). Chronicles of the Rotary Internship. Teaching and Learning, before and after the pandemic. Azuay: University of Azuay.

De Bortoli Cassiani, S., Munar Jimenez, E.F., Umpiérrez Ferreira, A., Peduzzi, M., \& Leija Hernández, C. (2020). The situation of nursing in the world and the Region of the Americas in times of the COVID-19 pandemic. Letter to the editor. Rev Panama Public Health, 44.

Espín-Arguello, AP (2020). Analysis of biosafety against the COVID-19 pandemic and the psychological impact on nursing professionals. Pol. With, 5(12), 29-38.

Fischer, T. B. (1999). Comparative analysis of environmental and socio-economic impacts in SEA for transport related policies, plans, and programs. Environmental impact assessment review, 19(3), 275-303. https://doi.org/10.1016/S0195-9255(99)00008-6

Haines, A., Kovats, R. S., Campbell-Lendrum, D., \& Corvalán, C. (2006). Climate change and human health: impacts, vulnerability and public health. Public health, 120(7), 585-596. https://doi.org/10.1016/j.puhe.2006.01.002

Jungheim, E. S., Ryan, G. L., Levens, E. D., Cunningham, A. F., Macones, G. A., Carson, K. R., ... \& Odem, R. R. (2010). Embryo transfer practices in the United States: a survey of clinics registered with the Society for Assisted Reproductive Technology. Fertility and sterility, 94(4), 1432-1436. https://doi.org/10.1016/j.fertnstert.2009.07.987

Kistan, K., Malka, S., \& Musni, M. (2020). The relationship between knowledge, attitude, and readiness of academic community in Covid-19 spread prevention: Batari Toja Nursing Academy, Watampone. International Journal of Health \& Medical Sciences, 3(1), 72-78.

Kumaran, S., \& Carney, M. (2014). Role transition from student nurse to staff nurse: Facilitating the transition period. Nurse education in practice, 14(6), 605-611. https://doi.org/10.1016/j.nepr.2014.06.002

Loor Quiñonez, T.I., \& Herrera Velázquez, M. del R. (2020). Causes of Contagion by COVID 19 in Nursing Interns. UNESUM-Science. Multidisciplinary Scientific Journal, 4(3), 59-68.

Martín Sánchez, A. (2019). Stress factors in nursing students during clinical practices. Nure Inv, 16(99), 1-10.

McCaughey, C. S., \& Traynor, M. K. (2010). The role of simulation in nurse education. Nurse education today, 30(8), 827-832. https://doi.org/10.1016/j.nedt.2010.03.005

Mera Navarrete, M.J., Mesa Cano, I.C., Martinez Suarez, P.C., \& Ramirez Coronel, A.A. (2021). Psychological impact on COVID-19 in nursing interns in pre-professional practices. Science and Technology University, 25(109), 53-59.

Merchan Merchan, N.L., Meza Huayamave, M.A., Palma Vásquez, J.G., \& Zambrano Velez, Z.D. (2020). Emotional health of nursing interns during the COVID-19 pandemic. UNESUM-Sciences, 4(3), 93-98.

Ngomane, S., \& Mulaudzi, F. M. (2012). Indigenous beliefs and practices that influence the delayed attendance of antenatal clinics by women in the Bohlabelo district in Limpopo, South Africa. Midwifery, 28(1), 30-38. https://doi.org/10.1016/j.midw.2010.11.002 
Pizarro Pereira, J., Yunda Aguilar, L., \& Chamba Tandazo, M. (2021). Psychological impact on nursing students of the rotating internship during the COVID-19 pandemic. Pole of Knowledge, 6(8), 242-256.

Sisalema Ana Luisa, A.Y. (2021). Experiences lived by rotating nursing interns who were infected with COVID19. Ocronos, 3(8), 26.

Stern, J. E., Cramer, C. P., Garrod, A., \& Green, R. M. (2001). Access to services at assisted reproductive technology clinics: a survey of policies and practices. American journal of obstetrics and gynecology, 184(4), 591-597. https://doi.org/10.1067/mob.2001.111793

Suryasa, I.W., Rodríguez -Gamez, M., \& Koldoris, T. (2021). Get vaccinated when it's your turn and follow local guidelines.International Journal of Health Sciences,5(3), x-xv. https://doi.org/10.53730/ijhs.v5n3.2938

Tapia, S. J. C., Guiza, M. N. V., López, J. I. R., \& Vargas, P. A. F. (2021). Nursing education in Latin America and virtual learning enviroments during a pandemic. CuidArte, 10(20), 19-30.

Veletanga, J. (2020). Concern in Medical Sciences students due to lack of clarity about the rotating internship. Edicionmedica.Ec.

Wang, F., \& Luo, W. (2005). Assessing spatial and nonspatial factors for healthcare access: towards an integrated approach to defining health professional shortage areas. Health \& place,11(2), 131-146. https://doi.org/10.1016/j.healthplace.2004.02.003

Widana, I.K., Sumetri, N.W., Sutapa, I.K., Suryasa, W. (2021). Anthropometric measures for better cardiovascular and musculoskeletal health. Computer Applications in Engineering Education, 29(3), 550561. https://doi.org/10.1002/cae.22202

Macías, M. L. C., Velázquez, M. del R. H., Alvia, A. M. M., Avila, G. M. R., \& Alvia, M. J. M. (2022). The nursing internship in COVID-19 times. International Journal of Health Sciences, 6(1), 398-404. https://doi.org/10.53730/ijhs.v6n1.4627 


\section{Biography of Authors}

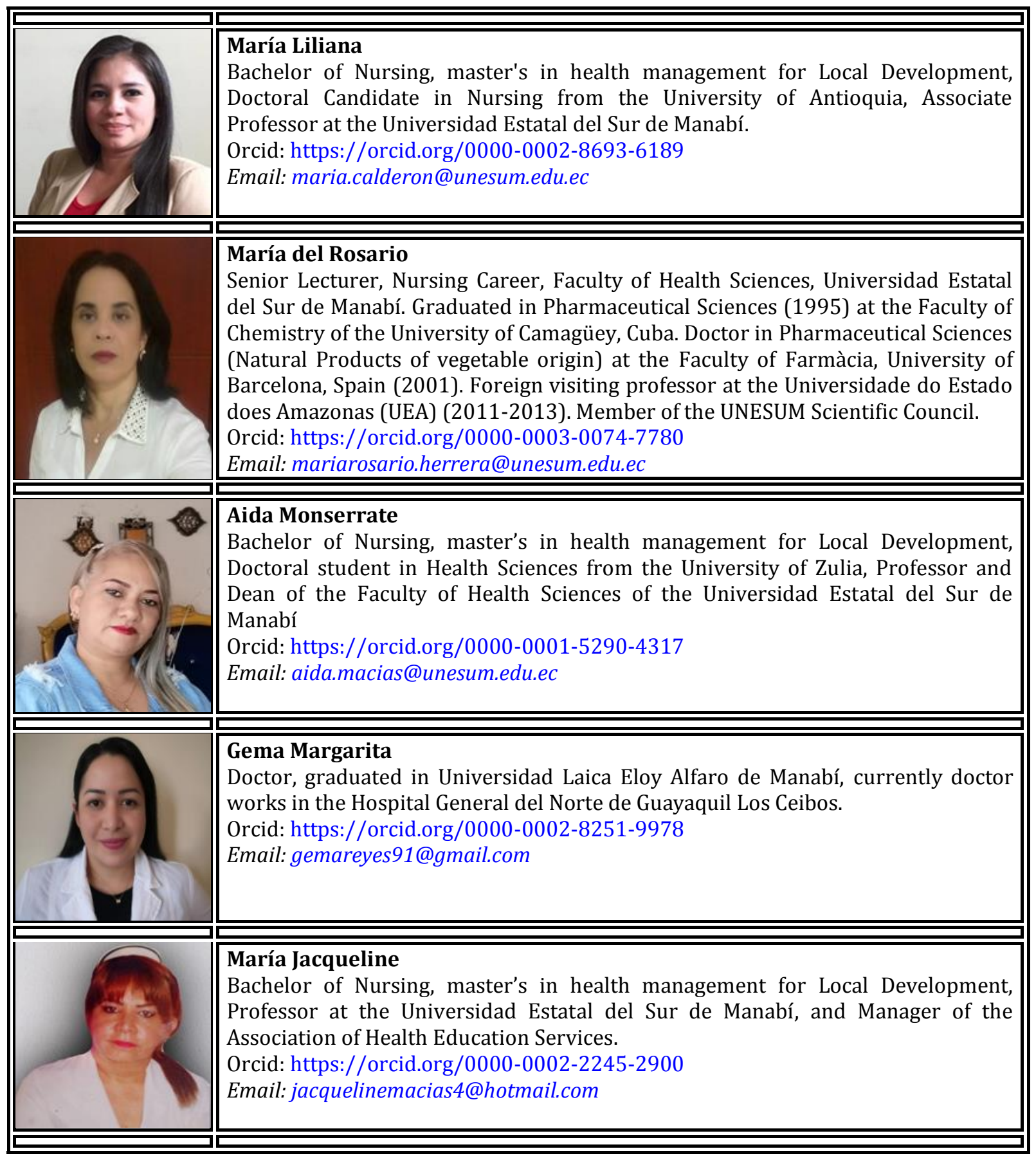

